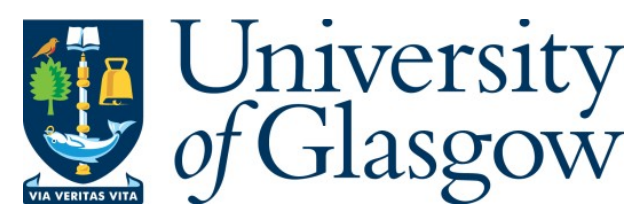

Wingrave, M. (2016) Perceptions of gender in early years. Gender and Education, (doi:10.1080/09540253.2016.1258457).

There may be differences between this version and the published version. You are advised to consult the publisher's version if you wish to cite from it.

http://eprints.gla.ac.uk/131798/

Deposited on: 23 November 2016

Enlighten - Research publications by members of the University of Glasgow http://eprints.gla.ac.uk 
UNIVERSITY OF GLASGOW

\title{
Perceptions of gender in Early Years
}

\author{
Author: \\ Dr Mary Wingrave \\ mary.wingrave@glasgow.ac.uk \\ School of Education College of Social Sciences \\ University of Glasgow \\ St Andrew's Building Room 618 \\ 11 Eldon Street, \\ Glasgow G3 6NH
}

Tel: $+44(0) 1413308156$

This article presents an exploration of a group of Early Years Practitioners' (EYPs) perceptions of gender that may provide some insight into the growing divide between boys' and girls' educational performance (Burusic et al., 2012). I argue that the current media and educational interest in the gendered brain (Sax, 2005) and the influences that surround the child (Eckert and McConnell, 2013), can result in children acquiring social expectations and attitudes to learning that are different for both sexes. The frequent dimorphic treatment of boys and girls is often based on assumed biological differences (Baron-Cohen et al, 2004) that suggest that the sexes learn differently. This can result in the approaches to the care and education of children being established on their sex categories rather than their individual needs. My focus here is to explore practitioners' expectations and understanding of children's behaviour and learning in the nursery environment. The study is premised on the belief that practitioners' perceptions of gender could, as argued by Eliot (2009), result in self-fulfilling prophecies being (re)produced and (re)created. The deployment of stereotypical assumptions and practices could, I suggest, limit children's opportunities. The data used here is drawn from my doctoral study of the nature of gender as was understood by eight EYPs who took part in five discussion group sessions. An interpretative paradigm was adopted, where the EYPs' discussed their experiences and understanding of gender from their practice. Following Holloway and Wheeler (2013), the study explored experiences and perceptions in order to illuminate meaning and understanding. The findings indicated that there is a belief amongst the group of practitioners with whom I worked that gender is either innate or learned and that EYPs play no role in its development. The tentative conclusions suggest that changes to the education and training of EYPs are required in order to raise awareness of gender issues in nurseries. I suggest that there is a need to place gender back on the education and training agenda for EYP in order to support changes to practice that could, in turn, provide children with more equitable teaching and learning experiences. 
There are many who would argue that ' $(\mathrm{g})$ irls have not only achieved equality, but superiority.

(Sadker and Zittleman, 2009:51).

Introduction

According Sadker and Zittleman (2009) gender for some is no longer an issue and that equality has been achieved. For others ‘equal but not the same’ (Sama, 2013: online) has become an accepted view of the sexes, where particular and distinct needs, learning styles and roles in society are believed to be innate. Some of the arguments used to support these perceptions emerge from previous discourses about the nature of men and women, whilst others are new and use modern technology to suggest proof of these theories. In this research I engaged with practitioners to discover how they understood gender. I did not enter the process to claim to have discovered that Early Year Practitioners (EYPs) exhibit gendered practices; rather I wanted to explore how EYPs, like other groups in society, 'do’ gender. It is important to acknowledge that whilst gender is the focus of this study, I do not suggest that it should or could be studied as a 'discrete' issue, separate from other key systems, categories or structures in society. I acknowledge McCall's (2005:1771) caution of the 'limitations of gender as a single analytical category', noting that, of course, gender intersects with other aspects of being for example: class, colour, ability, age, ethnicity and religion. Collins (2000) claims that areas of intersectionality reinforce and overlap with each other resulting in complex interactions and intersections which lead to different experiences and concepts of identity, it is the intersection of gender with these that can lead to inequalities. Whilst I did not adopt the methodology of intersectionality to study the 'relationships among multiple dimensions and modalities of social relationships and subject formations'(McCall,2005:1771) in this study, I nonetheless acknowledge its importance. For the purposes of this research how gender is understood is considered and viewed discretely in order to understand why some perceptions and theories of difference exist between the sexes and can have powerful effects on those who teach, care and nurture children.

In this I research sought to discover if EYPs were aware that they could be conveying stereotypical assumptions and practices that could be perpetuating particular images of boys 
and girls. My concern was based on Ruble et al's. (2007) concern that theories can become truths that can become self-fulfilling prophecies, as over time truths can become practices that are so embedded they often go unchallenged. Thus, the very sector charged and trusted with promoting justice through education and care may, through the adoption of pseudoscientific practices or blindness to practices, reproduce the old rhetoric that boys and girls are immutably different and require different educational experiences. How gender is done depends on how it is perceived by those who influence and nurture children's development in the world (Lynch, 2015).

Here, two main approaches to gender are examined: biology which it is claimed determines the differences between the sexes and socialisation which considers that the majority of differences are determined by the environment and relationships.

\section{How gender can be viewed: Biological determinism}

According to Moi(1999) biological determinism views gender differences as originating from biological or evolutionary origins. LeMay Sheffield (2004) notes that Aristotle advised that the significant biological differences between men and women were founded on their reproductive capabilities, which dictated that women and men had separate and different social roles and zones. According to O’Brien (2009), the first sustained questioning of sex as a fixed biological and social determining factor was during the Enlightenment period, which provided opportunities for the historical and philosophical questioning of traditional, political and social positions of men and women. The discussions that emerged from this period created a structure and a language for understanding gendered organisations of society (ibid). McRobbie (2004) optimistically suggests that many feminist aspirations of equality and recognition for women have been successfully been assimilated into Western society in the $21^{\text {st }}$ Century through the struggles of feminism in successive generations. As the quote at the start of this article suggests there are some who believe that women are now viewed as superior to their male counterparts (Sadker and Zittleman, 2009). However, whilst women's experiences and opportunities have altered and been embraced in relation to a progressive societal understanding of feminism (ibid) biological determinism has once again been raised and supported with the use of modern technology. This focus and determination to return to biological determinism could, as eloquently put by Davies (1998:131), result in society 
'knitting back up the unravelled world of the old discourses with every pattern we thought we had just pulled undone’.

Functional magnetic resonance imaging, commonly known as fMRI scanning, produces images of the brain that show the changes in blood oxygen levels relating to brain activity. This imaging, according to Schoning et al. (2007), allows claims to be made about cognitive activity and do appear to indicate sex differences in the development of the brain that appear to manifest in early in childhood (ibid)suggesting that there may be innately fixed differences between male and female brains. These differences, it has been proposed by researchers such as Baron-Cohen et al. (2004) and Wolpert (2014), have developed over the course of evolution and could have become incorporated into human development either through hormones that babies are exposed to prenatally or through genetic differences. According to Sax (2005:28), biology and the brain explain everything: '(g)irls and boys behave differently because their brains are wired differently’. It would therefore appear that fMRI scans provide the proof that many have been looking for to show that males and females are fundamentally different.

Further, Lenroot et al. (2007) note that female and male brains differ in areas such as size, white or grey matter and images produced by fMRI scanning. Kimmel notes that in 'the ratio of brain surface to body surface...men's brains would 'win' but...the ratio of brain weight to body weight, women's brains would appear superior' (2005:31). Haier et al. (2005) observed that white matter is generally associated with women's aptitude and grey matter relates to men's but exactly why different parts of the brain are used by the sexes remains unanswered. As such, Haier et al. (ibid) advocate caution when drawing conclusions from their work and they state that further research and observations needs to be undertaken before theory relating to why these differences exist can be formulated.

Schmidtz (2010) claims that when examining the brain its plasticity ${ }^{1}$ and malleability needs to be considered as it appears that experiences in terms of the relationships and environments in which a child is nurtured plays a significant role in the changes that occur in the brain's

\footnotetext{
${ }^{1}$ Plasticity refers to the brain's ability to change as a result of experiences.
} 
neurological pathways over time. Schmidtz (ibid: 70) argues that experiences have profound effects on the brain, which can affect how it continues to develop and can result in particular pathways being formed. If, as Millett (1971) famously argued, experiences are fundamentally different for girls and boys it is not surprising that males and females show different brain patterns.

It has been suggested that '...there is a far greater range of differences among males and among females than there is between males and females' (Kimmel, 2005:33) and there appears to be no firm evidence that the differences observed in male and female behaviours, cognition or preferences are due wholly to biology. However, claims made by some (for example, Sax, 2005: Wolpert, 2014) that fMRI scanning provides definitive proof that the differences observed in the male and female brain confirm they are innate, recommend different teaching and nurturing approaches for boys and girls. This advice may in fact be creating and reinforcing many of the observed differences.

Eliot (2009), also observed that nurture in the form of life experiences can become nature, where biological or physiological changes occur in the brain and can be seen by fMRI scans. This suggests that neurological pathways are not fixed and that with exposure to new and different experiences the brain can change, with the possibility that if new experiences are introduced then new pathways can be created.

This leads to the examination of the social construction of gender as Schmidtz (2010) and Eliot's (2009) findings, suggest that experiences impact on the development of neurological pathways in the brain. Thus, where fMRI scans show differences in male and female brains and similarities in brains of those of the same gender, these could be the result of gendered practices that reinforce particular behaviours and preferences.

\section{Influence of Socialisation.}

Collins (2000) suggests that gendering begins at birth and continues throughout life. Further that adults pass on to the child their particular societal knowledge about gender. Thus, each child is taught a particular gender script that reifies their sex. This is learned through the adults' behaviours and actions towards the child which reflect the adults' own expectations and views of what it is to be a boy or a girl. Ryle (2012) notes that there are many social norms about how boys or girls are treated—some may encourage their girls to be 'girlie girls' 
whilst others do not-results in variations of expectations and responses. However, societal trends still have an influence that result in some gendered practices being perpetuated whilst other practices change and shift over time (Massey, 2013).

Many studies suggest that the adults induct children into their gender roles through social interaction (ibid). However, exactly how this learning takes place is widely debated and it is acknowledged that there are many theories of social learning which cannot all be covered within the scope of this paper. Therefore, a focus on Gender Schema Theory (GST) will be presented as it seeks to understand how children learn to gender in the society and culture in which they live through the development of cognitive 'schemas'.

\section{Gender Schemas}

Schemas can be understood as 'mental structures children use to encode and process information' (Siann, 1994:73). Lipsitz-Bem(1983) claims that children of two to three years old will start to relate to binary categorisations of male and female. Additionally, Martin and Halverson (1981) suggests that children organise and attach meaning to the information observed. This gendering process is assumed to start when the child is able to classify her/himself as one of the binary categories. Weinraub et al. (1984) observed that as children advance in mobility and cognition their awareness of gender increases through observation and the modelling of actions of those of their own sex. Leinbach and Fagot(1993) suggest that the development of gender schemas can begin as early as one-year-old and the child being able to recognise her/his sex allows her/him to develop an awareness of the gender stereotypes that exist in the surroundings.

Shaffer (2009:20) argues that children also control and create their own gender identity and that they are able to regulate and construct rules about the 'other' gender. This could help explain why some children acquire very different views, interests and skills as they develop; it also explains why some children —and adults — have flexible views towards gender roles and behaviours whilst others have very fixed views. The construction of rules may also provide some insight into why some people who live in the same society will defy gender stereotypes and are critical of sexism whilst others continue to reinforce and perpetuate the status quo (Swim and Hyers, 2009). the child evaluating situations or behaviours based on their own cognitive reasoning. For example, a boy may observe that it is girls who tend to dress up and that it is they who receive positive feedback from adults for this activity. 
However, based on his self-schema, which tells him that he enjoys and has fun dressing up, he may continue to play dress up despite the lack of positive feedback or in some cases negative feedback. The evaluation of an activity by the child explains why some children do not always conform to the norms expected by the adults. Tobin et al. (2010) claim that learning gender is complex and that gender is acquired through social interaction where there is a combination of the internalisation of gender identify, the assimilation of gender stereotypes which inform the child about gender expectations and each child's unique experience of gender, thus gender acquisition is both an individual and a societal experience.

Eckert and McConnell, (2013) observation of adults noted that children's behaviours are confirmed or negated by the adults as being that of a boy or of a girl. This socialisation can result in children learning social expectations that are different for both sexes and that are supported by obvious and oblique, intentional and unintentional influences from families, friends, schools and the media(ibid). Further, Trawick-Smith et al. (2015) found that gender play differences are evident during free play. Boys and girls, even when playing with the same toys, engage differently with the toys along gender lines and the quality of play appears to promoted different skills. Suggesting that children may learn to play with toys from significant adults who inculcate and promote particular gender behaviours. This is also reflected in Lynch's (2015) research in to the gendered attitudes and expectations of kindergarten teachers' which found that the adults' assumed gendered expectations about the children's conduct influenced the pre-school children engagement and behaviours with the play activities. It is recognised, as noted by Chappell (2011), that there is no setting that is a wholly neutral space and that gender behaviours are learned, modified and reproduced in all areas of children's lives as a result of gender specificity existing in all institutions.

\section{Learning Gender in the pre- 5 setting}

O’Brien et al. (2000), observed that girls and boys learn and think about being male and female differently in response to the ways in which these qualities are presented to them in social contexts. Gestwicki and Bertrand (2011) claim that the nursery environment is the first sustained institutional encounter, beyond the home, where children experience society's expectations about gender. As such, EYP play an important role in the schemas and stereotypes that children develop (Robson, 2012). Fundamental in this process, according to Erden and Wolfgang (2004), is the practitioners' own beliefs and attitudes about gender 
because these, along with other factors as discussed above, play a significant role in what children learn. Hilliard and Liben (2010) suggest that children quickly absorb and replicate the gendered opinions of the adults around them and they then start to organise themselves according to these gender categories. Thus, practices and resources in the playroom can lead to gender stereotypes and divisions that produce two distinct cultures for boys and girls. This can, after even short exposure, strengthen gender beliefs and subsequently lead to segregation and a variance of expectations (ibid).

According to Laevers and Verboven (2000), children's entry into the education and care system results in gender differences extending and being more openly expressed. Play, they observed, quickly conforms to widely held gender stereotypes, with girls playing with creative activities whilst boys tend to play with physical activities(bid). Laevers and Verboven (2000:28) note that the physical materials that are used to support learning and play often continue to depict traditional stereotypes. They conclude that all materials used should be selected with care and caution to avoid re-emphasising these. Another site of gendering is the structure and organisation of the setting. Early Years, internationally, is a profession which is predominately female, often as a result of care being viewed as the domain of women and the pay and conditions often not rewarding enough to attract male practitioners (Peeters, 2013). Moss (2003) notes that it is predominantly women who provide professional childcare and that in education more broadly the age of the child correlates to the percentage of women in that area, with early years being staffed by $97.5 \%$ women compared to $55 \%$ in the secondary sector.

However, one of the main concerns focuses around the messages conveyed by adults to children which often conform to many of the stereotypes about gender as these can, along with other external factors, result in the perpetuations and replication of gendered expectations and behaviours. (Ärlemalm

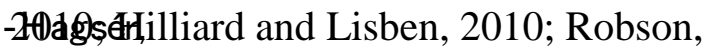
2012). Behaviours often highlight that the sex of a child is not only an important factor, but in fact one that will shape their treatment and place in society's order with Laevers and Verboven (2000:28) claiming that practitioners responded to boys more often and tend to present them with more challenging activities than they did to girls. Dobbs et al. (2004) observed that EYP often value girls' behaviour more highly than boys’ behaviour claiming girls are better behaved and calmer than the boys. 
This suggests that the adults in the pre- 5 sector treat boys and girls as distinct homogenous groups where there are different expectations and norms based on the children's sex category. If this is the case, it would appear that those who work in the pre-5 settings could be contributing to the reinforcement of traditional stereotypes. Ärlemalm '-H(ag)dê:519) research, and that of others (for example, Hilliard and Lisben, 2010; Robson, 2012), suggests that the relationships developed in the playroom result in the adults' understanding and consideration of gender being conveyed to the children, who can quickly absorb and recreate them. Erden and Wolfgang (2004) also opine the beliefs and attitudes of practitioners play an important role in what children learn about gender and that a starting point for any change requires the development of a heighten awareness with those involved with children so that they become aware of their own beliefs and behaviours. It is from these understandings and concerns that this study was initiated. The study seeks to identify perceptions which may indicate variations of practice based on perceived or assumed differences between boys and girls. In the next section, the methodology and methods used to explore a group of EYPs' understanding and attitudes towards gender is presented.

\section{Methodology, methods and analysis}

\section{Research purpose and methodology}

The intention of this project was to discuss with a group of eight EYP their views and attitudes to gender. After ethical approval was given by the University of Glasgow, I sought to recruit the participants for the project. The students were BA students studying for an undergraduate qualification in Childhood Practice (SSSC, 2015) ${ }^{2}$. These students all had practice qualifications and were experienced EYP, who due to registration requirements, were required to complete a Scottish Certificate and Quality Framework ${ }^{3}$ (SCQF) Level 9 qualification as a Leader and Manger (SCCC, 2015) ${ }^{4}$. In order to gain entry to the degree programme students were required to be in practice for a minimum of four years.

The group involved in the research were all women, which both reflects the demographic of the workforce (Rodd, 2012) and the profile of the programme. The First Year students on the

\footnotetext{
${ }^{2}$ Childhood Practice consists of students who are leaders and managers in non-compulsory children services; this includes those who work in Early Years, Residential Children's Homes, Women's Refuges and Out of School Services.

${ }^{3}$ SCQF Level 9 is equivalent to an ordinary degree.

${ }^{4}$ SSSC registration requirements for Leaders and managers in Childhood Practice settings: http://www.sssc.uk.com/registration/do-i-need-to-register/is-registration-compulsory
} 
programme were asked to opt in to the research project through a message on the University’s virtual learning environment. This group was selected as I had not yet taught them and I would not be responsible for the marking of their current course work. My requested was that participants should come from the EY sector of Childhood Practice and I selected the first class group in which eight students responded to the posting. The eight participants were asked to attend four discussion groups followed by a feedback session as part of my doctoral research where further themes were uncovered and discussed. The presentation of the themes in this paper permeated all the discussion groups.

This grouping was adopted to obtain insights from the practitioners' perspective (Burrell and Morgan, 1979) of gender development in their nurseries which allowed the generating of qualitative data. This followed advice from Holloway and Wheeler (2013) who suggest that although there is no optimum or definitive number of participants in a discussion group, six to eight individuals would be adequate if those involved come from a similar sphere. Here the similar sphere was the individuals' membership of a learning cohort on the BA in Childhood Practice and their shared experience of working in EY.

Oates (2006) advises that the methodology should be chosen at the levels of ontology, epistemology and axiology, in order to situate the study within a suitable paradigmatic framework. Weaver and Olson (2006) claim that the paradigm allows beliefs and understandings to be articulated about the project and brings to the fore any assumptions and principles of the researcher. The ontology of this research assumed that those involved would not have one reality and that their experiences, and the meanings attached to these, would be individual 'truths' for them. The EYP's epistemology, their knowledge, was constructed through interactions and experience, which illuminated their perceptions of gender. This, according to Guba and Lincoln, (2005), would result in numerous truths. Further, these truths viewed along with Heron and Reason's (1997:287) explanation of the term axiology in social science research, acknowledged that 'human states are to be valued simply because of what they are' and that this should be considered in the context of people’s lives'. These understandings, allowed the project to be located in an interpretative paradigm. This method therefore acknowledged the experiences and perceptions of those involved are based in particular situations and come from individual understandings (Schutz and Luckmann, 1983). 
Congruent with the paradigm, the project illuminated opinions, experiences and observations of the EYPs' understanding of gender and it does not seek, nor claims generalizability or representativeness (Putman, 1983).

\section{The research group and protocols}

At the first session (DG1), the participants were given a Plain Language Statement which explained that the discussions would be recorded and a transcript of the recordings, along with notes indicating the codes and themes identified, would be sent by email to each participant. It was acknowledged that the participants could, if they wanted, suggest new themes for discussion or contest any of the interpretations made. Thus, the next iteration would be based upon the areas which emerged from the previous discussion, making the project data driven. Guba and Lincoln (2005) advise involving the participants in the production of the themes and explanations as it allows the information gathered to be credible, representative and authentic to them. Silverman (2006) suggests this approach would provide the participants with a chance to reflect on their former contributions and it would demonstrate the researcher's commitment to participants being valued in the process (Kezar and Dee, 2011). Groundwater-Smith and Mockler (2007), also advises that the participants should be encouraged to challenge and respond to the data collected and analysed in order to keep the project ethical. Despite the opportunities to respond the participants did not add to the themes although they did provide clarification of their contributions. This approach to practitioner research, where the participants are permitted to question the analysis of the data, makes it more credible and acknowledges the sensitivity of the researcher to the power relationships that existed between the researcher and the participants (Groundwater-Smith and Mockler, 2007).

\section{Data Analysis}

An approach described by Braun and Clarke (2006) as Thematic Analysis was used to examine the discussion group data. The analysis considered both the data and literature and theories to support the presentation of the findings. Analysis took place after each DG session, resulting in the process being undertaken in four parts as an inductive process, where as suggested by Denzin and Lincoln (2005) explanations shifted from interpretation which were explicit to broader generalisations. Following Hollinshead, (1996) this process was open-ended and cautious: I was not presenting or assuming conclusive 'answers'. This 
permitted themes to be created by the data and supported the production of the themes (Figure 1). Braun and Clarke (2006:89) suggest 'engagement with the literature can enhance your analysis', so throughout the process, theory reinforced the analysis and elucidated articulations allowing codes, categories and themes of transcripts to be created.

Corden and Sainsbury (2006:98) highlight the need for researchers to 'clarify the links between data, interpretation and conclusions' so after each DG the participants were sent a copy of the transcript along with its analysis. Each subsequent DG was based on the initial conclusions allowing time and scope for the group to confer (Morse and Richards, 2002).

The following section maps the findings and uses quotes and short group statements (SGS), to present the voices of the EYP responses and experiences of gender in their setting. At the start of the research everyone was asked to consider if they believed gender to be innate or whether they considered it to be created, although this topic was both explicitly and implicitly referred to throughout the DG meetings. The participants appeared to oscillate between a number of positions: explaining gendered behaviours, physical features, learning and attitudes to gender as being either biological or created by others. All the participants expressed unfounded biological deterministic views, which reflect traditional folk wisdom, and were institution based. Yet there was an acknowledgement that gender could be influenced and created by those beyond the nursery environment. Mixtures of beliefs, where ideas existed within other ideas or beliefs, presented a multi-layered understanding of gender which, at times, appeared to be muddled or contradictory. As discussed above this is because determining exactly where biological influences ends and where behaviours which are influenced by culture or environment begin is not possible.

The data and discussion that now follows focused on two aspects which underpinned the EYP discussions. Biological—where learning and specific behaviours were assumed to be biological and therefore 'naturally' associated with the sexes The other aspect focused on the recognised constructed aspect of gender-specifically relating to the parents of the children. Additionally, the practitioners claimed that they are gender blind and that owing to their training they do not contribute to children's gender learning.

\section{Biological}


...they say boys have a more logical brain which can accept maths and numbers more easily than girls can.

$$
\text { DG1RP1 } 1^{5}
$$

..baby boys have a different shape of head than baby girls

\section{DG1RP3}

I think from a young age wee boys and girls have a different manner in the way they come across

\section{DG1RP8}

These comments suggested that the participants believed that there are physical, biological and psychological differences which mark boys and girls out as being different. The comments showed a tendency to interchangeably use the terms sex and gender. This was similarly noted by Meyer (2010), who claimed that often the sex differences; male/female, boy/girl, are confused with socially acquired notions of masculine and feminine. It is possible that this confusion adds to, or has led to, assumptions that biological differences explain observed dissimilarities in learning and other aspects such as behaviours.

All the participants reported that there were particular attitudes and areas of learning they believed were natural and specific to the sexes. Table 1 illustrates reported gender preferences that girls and boys show towards particular learning. The participants all confirmed that boys take more time to settle to activities and that their concentration tends to be fleeting. Conversely, girls were associated with language and creative activities where they were reported as exhibiting more passive behaviours and the ability to focus for periods of time. Whilst it was generally proposed that the children display gender differences in their choices for where and what they learned, a few participants acknowledged that some children showed preferences which were opposite to the manner associated with their sex. However, these accounts were often presented as exceptions. The information presented illustrates the areas that the participants indicated what the sexes prefer. It should be noted that this table does not record the frequency of how often the sites were mentioned but rather records that reference to these locations were made and were not challenged by the other participants.

\footnotetext{
${ }^{5}$ DG1RP1 - Discussion Group 1 respondent 1
} 
The participants acknowledged and confirmed that nursery education practices are adopted to accommodate these perceived differences between the sexes, in order to meet the children's individual needs. Typically, an area underused by one of the sexes will be incentivised with the incorporation of a toy which is reported to be of interest to that sex:

I would say...for example we did tend to have a lot of boys playing in it (construction) so we put a castle in it...with some ponies so now the girls will build bridges for their ponies... and doing different things like that.

DG1RP8

This would suggest that this participant is aware of actively creating an environment which merges stereotypical toys in order to attract both sexes. The use of the castle and ponies will be an incentive to encourage the girls to play in an area traditionally associated with the boys as it is reported that the girls do not play in this area. According to Andersen and Taylor (2007), the environment in which a child plays conveys messages about norms and the reported behaviours here could be related to what popular research which argues that boys and girls are drawn to different activities due to innate biological preferences (see: BaronCohen, et al., 2004: Sax, 2005) rather than the areas themselves being stereotyped as areas for boys/girls to play in. The following SGS demonstrates the confirmation and affirmation that the participants give to each other to support commonly held opinions which give credence to and corroboration of biological differences requiring differentiated practices and approaches to the children's learning based on their sex:

Despite the popularity and appeal of theories which suggest and influence beliefs that there are fixed binary characteristics attributable to female and male learning, there is no categorical verification that there are particular neural processes which are inherently unique to boys or girls in the way they learn (for example, Lehrer, 2008; Eliot, 2009). As discussed by Kimmel (2005) the range of differences between the sexes is relatively small compared to the similarities which exist. The assumption that nature is the only cause of these differences will result in other possibilities, for instance, behaviours and preference being learned, being ignored or dismissed. This can result in fatalistic expectations where practices are based on presumed hard-wiring which cannot be altered. The participants' acknowledgement and confirmation of these supposed attributes for each sex, and their intentions to accommodate them to meet the needs of the children, could imply that the children are being taught to selfregulate their learning in an inherently gendered manner. Hence as described by Martin and Ruble (2009), behaviours and practices become inculcated and normalised for both in-groups 
and out-groups. This helps to signpost for the children which behaviours are appropriate for them. This in turn results in gendered practices and expectations, furthering the belief that the features of learning are natural, dependable and cannot be changed.

Across the DGs the participants also reported specific and different social and physical behaviours for boys and girls which are believed to be innate due to their consistent nature. The differences reported (Table 2) tended to focus on how the sexes settle into the nursery environment and the manner in which they exhibit social behaviours.

The participants all confirmed the claim that girls are emotionally more mature, are able to express their feelings and needs, and are calmer and have more developed fine-motor skills. Positive expectations were expressed in relation to girls' behaviours and their emotional development. In addition, the participants recount that boys were more physically active and exhibit better gross-motor development. The reported behaviours tended to conform to generally held stereotypes which depict girls as being more compliant than boys, who are livelier and who require more redirection (Jones and Myhill, 2004). These observations reflect Walters' (2010) concerns where she suggests that the sexes are often divided into two distinct groups where the exhibited behaviours could be viewed as the antithesis of each other and where their consistency is attributed to innate factors:

I know there's always a few exceptions but I think in general....I think girls come across a bit softer and a bit less rough than boys.

\section{DG1RP8}

There was a consensus that the observed differences between the sexes inform teaching and learning and that these are sometimes exploited to optimise learning and development for boys and girls.

For boys who are always at the dinosaurs or always at the blocks and if you have a certain thing you have got to teach...you have to improvise and maybe use that area to do the teaching in. If they wanted to learn...you're going to improvise and do something...in the areas that they like.

DG3RP5

Sites of learning and play which adopt approaches consistent with the sex of the child can result in the child experiencing a specific environment where they learn particular 
behaviours, attitudes and proficiencies (Walters, 2010). This can result in a very focused and limited environment for learning where the child develops scripts which allow them to operate in and interact appropriately with that environment. This it could be argued maintains and creates specific expectations and norms of behaviours and aptitudes. Freed (2003) cautions that children can develop schemas of socially acceptable behaviours, which can be interpreted as being the result of biological qualities rather than learned because they appear to be consistent in how they manifest themselves. This suggests that what adults do could be responsible for the reinforcement of behaviours, learning and attitudes resulting in them appearing to be innate (ibid). The practitioners' responses, concerns and attention can therefore highlight behaviours which are consequentially reinforced. However, as previously signposted, the participants do not view all behaviours as innate. There is recognition that some aptitudes and preferences are the result of the influence of parents and others, although the participants expressed the belief that EYPs do not generally contribute to this development. The next section focuses on the construction of gender as described by the practitioners and evident in the DGs transcripts.

The participants suggest that often parents exhibit fatalistic attitudes towards their son's behaviours and when they are very small some parents appear to positively reinforce boisterous and active behaviour in boys. When discussing parents' comments and behaviours little is said about girls, as the discussion focused primarily on boys and their behaviours:

...whereas mums of boys tend not to care because that is what boys do.

DG3RP7

Participants' comments also illuminate different attitudes of mothers and fathers towards the sexes. Once again the results presented here do not represent frequency counts, rather they are comments made and agreed or developed by the participants. From the descriptions two distinct worlds are created:

The world of a girl is depicted as a quiet clean haven where she is protected by men while she looks after the needs of others. The views of mothers as reported by the participants focus on how girls should appear to the world. This is in contrast to the fathers' views which depict their daughters as being decorative and fragile, in need of protection. However, boys distinctly appear to inhabit a world where they are active and motivated and engaged. The mothers' views presented by the participants depict boys whose behaviour is endorsed as 
masculine. The fathers are reported as encouraging masculine behaviours and there are indications that the boys should be protective of females. The worlds created here conform to well establish documented beliefs about females being passive and males being active (for example, Rubin, 1975) and resonate with the findings of Snow, Jacklin and Maccoby in 1983 who found that fathers tend to be more boisterous and engaged in rough-and-tumble play with their sons. However, whilst the reporting of these attributes depict inherently stereotypical attitudes displayed by the parents, it is important to emphasise that these are assigned by the participants to the parents.

The stereotypical views presented above in SGS2, by the participants perhaps may be more representative of the participants' opinions and perceptions of the parents' behaviours and parenting habits rather than truly reflecting the parents’ opinions and attitudes.

All the participants maintain that they do not see the children as boys or girls; rather they view them as individuals. As with other elements of the discussions, there are contradictions and inconsistencies. As discussed by Morgan (1997), this was to be expected in this method of gathering data as the participants' reflected upon their ideas and thoughts during the DGs. The main areas of contention are illustrated in Table 4 and each area will be examined in this section:

Participants typically express the view that whilst children are treated equally, there is a requirement that the sex differences which exist should be highlighted as part of the children's education: In addition to this, the participants acknowledge that there are times when they respond to the sexes differently and that knowing if a child is a boy or a girl will allow them to respond to the child appropriately. Despite this, the participants do not believe that they create a gendered environment and as professionals they do not gender. The offloading of gendered behaviours as the responsibility of others and the mitigating factor of the children's ages — they are small—alongside the training the participants receive, all help to reconcile the power of gender with their own individual professional agency. The participants do not believe they are influential nor do they believe they contribute to gender as they consistently reported that children are not treated differently from each other in the nursery. Citation of the individual child and responding to the needs of the child are used to explain that there is no intention to encourage or discourage gendered type behaviours or learning. 


\section{Conclusions}

I think a nursery is always a totally different environment because we have the training and we understand...

DG4RP8

All the participants expressed the view that the nursery and the staff provided a haven, exempt from playing any role in the children's development of gender. It is not until DG3 that some acceptance and recognition of their potential role in the gendering process emerged, but this was not sustained and by DG4 it was evident that the participants held the belief that the nursery uniquely provided a gender free environment. The discussions illustrate that 'nature versus nurture' arguments about gender are prevalent and contribute to the practitioners' understanding of boys and girls in the nursery although it appears that often little or no specific theory underpins the views offered. However, the data suggests that the participants are aware that gendered expectations can result in the limiting of what children can become based on beliefs about the nature of boys and girls but that parents are predominately responsible for this gendering. Further, the belief that parents determine the children's gendered behaviours before they enter the nursery environment appears to result in a resignation that there is little the nursery staff can do about reversing these more pervasive influences.

Kimmel (2005) argues that the range of differences between the sexes is relatively small compared to the similarities which exist. The assumption that nature is the only cause of these differences will result in other possibilities, for instance, behaviours and preference being learned, being ignored or dismissed. This can result in fatalistic expectations where practices are based on presumed hard-wiring which cannot be altered. The participants' acknowledgement and confirmation of these supposed attributes for each sex, and their intentions to accommodate them to meet the needs of the children, could imply that the children are being taught to self-regulate their learning in an inherently gendered manner. The general feeling expressed by all the participants was that as they were trained professionals, they were in some way immunised against transference of gendered messages. There was acceptance that some aspects of gender could be constructed but that this was the results of parental practices. The EYP believed they could protect the children by insulating and redressing these malignant influences through their non-gendered practices.

The recorded gender blindness of the participants provided an insight into the belief that gender messages are conveyed by others and not them. However, the analysis illustrates that 
EYPs are no more and thereby no less gendered than any practitioners in any other institutions or professions. This has implications for the expectations and norms conveyed to the children as these consequently impact upon the children's development and acceptance of the nursery's gendered practices.

\section{The Future}

Branisa et al. (2010) caution that a world that accepts asymmetrical stereotypes will (re)produce parallel worlds which are differentiated by power. Unless these can be disrupted these stereotypes, boys and girls, and men and women, will continue to see each other as opposites. Acceptance of equal but different fails to recognise individuals as, primarily, human beings rather than boys or girls, men or women. I suggest these beliefs can result in the (re)creation and (re)production of stereotypes associated with what it is to be male and female. Consequently, parallel experiences based on the sex of the children may be constructed.

In order that transformative change can take place in nurseries, I argue that EYPs should consider both gender theory and practice in order to support a defamiliarisation of gender, where it is necessary to eliminate the damaging acceptance of stereotypes and folklore assumptions along with essentialist principles that continue to produce and reinforce polarized and gendered dichotomies. This can be done by considering the training of all those entering the profession and the need to highlight and challenge practices and attitudes which accept that girls and boys should play in particular and separate areas or that girls and boys have particular strengths due to their sex category

Further, gender education needs to focus on both new practitioners and the ongoing development of reflective EYPs as part of career long professional learning. Programmes should encourage EYPs to identify practices which can lead to the development and creation of stereotypes. As society and technologies change so do concepts and understandings of gender where new and different biological deterministic views emerge which continue to divide society. It is therefore important that everyone in education takes responsibility: researchers, further education colleges, universities and those who are involved in the creation of policies to support ways of conceptualizing and defining practice by challenging and re-directing gendering. 
For as long as those who work with young children continue to view boys and girls as immutably different, rather than as individuals then children will experience and continue to replicate social norms in two different and two gendered worlds. Through well trained enlightened practitioners, children can be offered experiences that can offer multiple and fluid understandings of what it is to be an individual. Such understandings could mean that girls are no longer positioned as the inferior 'other' or the compliant, quieter, cleaner version of males or that boys are not defined by limited understandings of masculinity. Rather, an acceptance of a variety of play behaviours for both boys and girls would be seen as a healthy expression of exploration and learning. Putting gender firmly back onto the education and training agenda for EYPs, could help to enable this workforce in the provision of a socially just, stimulating and creative learning space for all children.

\section{References}

Andersen, M, L. and Taylor, H.F. (2007) Sociology with Infotrac: Understanding a diverse society, casebound $\left(4^{\text {th }}\right.$ ed). Belmont, California, USA: Thomson Wadsworth.

Ärlemalm-Hagsér, E. (2010) 'Gender choreography and micro- structures early childhood professionals' understanding of gender roles and gender patterns in outdoor play and learning'. European Early Childhood Education Research Journal, 18(4), pp. 515-525

Baron-Cohen, S., Lutchmaya S. and Knickmeyer, R. (2004) Prenatal testosterone in mind: Amniotic fluids studies. Massachusetts, USA: Masssachusetts Institue of Technology.

Branisa, B., Klasen, S., and Ziegler, M. (2010) 'Why we should all care about social institutions related to gender inequality.' University of Goettingen Department of Economics@ @ http://www.econstor.eu/bitstream/10419/39965/1/343_branisa.pdf (last accessed 18/3/16).

Braun, V. and Clarke, V. (2006) 'Using thematic analysis in psychology'. Qualitative Research in Psychology, 3 (2), pp. 77-101.

Burrell, G. and Morgan, G. (1979) Sociological paradigms and organisational analysis: Elements of the sociology of corporate life. London: Heinemann.

Burusic, J., Babarovic, T. and Seric, M. (2012) 'Differences in elementary school achievement between girls and boys: Does the teacher's gender play a role?' European Journal of Psychology of Education, 27(4), pp. 523-538.

Chappell L.(2011) 'Nested newness and institutional innovation: Expanding gender justice in the International Criminal Court'. In: M. L. Krook and F. Mackay (eds) Gender, politics and institutions. Basingstoke: Palgrave Macmillan, pp.163-180.

Collins, P. H. (2000) 'Gender, black feminism and black political economy’. Annals of the American Academy of Political and Social Science, 568(1), pp. 41-53.

Corden, A. and Sainsbury, R. (2006) 'Exploring 'quality': research participants’ perspectives on using quotes'. International Journal of Social Research Methodology, 9(2), pp. 97110. 
Davies, B. (1998) 'The politics of category membership in early childhood settings'. In N. Yelland (ed) Gender in early childhood. London: Routledge, pp. 131- 148.

Denzin, N. K. and Lincoln, Y. S. (2005) The Sage handbook of qualitative research. ( $\left.3^{\text {rd }} \mathrm{ed}\right)$. London: Sage Publications Limited.

Dobbs, J., Arnold, D. H. and Doctoroff, G.L. (2004) 'Attention in the preschool classroom: The relationships among child gender, child misbehavior, and types of teacher attention'. Early Childhood Development and Care, 174(3), pp. 281-295.

Eckert, P. and McConnell, G. S. (2013) Language and gender ( ${ }^{\text {nd }}$ ed). Cambridge: Cambridge University Press.

Eliot, L. (2009) Pink brain, blue brain: How small differences grow into troublesome gapsand what we can do about it. New York, USA: Houghton Mifflin Harcourt Publishing Company.

Erden, F. and Wolfgang, C. H. (2004) 'An exploration of differences in prekindergarten, kindergarten, and first grade teachers' beliefs related to discipline when dealing with male and female students'. Early Child Development and Care, 174(1), pp. 3-11.

Freed, A. (2003) ‘ Epilogue : Reflections on language and gender research'. In: J. Holmes and M. Meyerhoff, Handbook of language and gender. Oxford: Blackwell Publishing. pp.699 -721.

Gestwicki, C. and Bertrand, J. (2011) Essentials of early childhood education (4 $\left.{ }^{\text {th }} \mathrm{ed}\right)$. Toronto, Ontario, Canada: Nelson Education Ltd.

Guba, E.G. and Lincoln, Y.S. (2005) 'Paradigmatic controversies, contradictions and emerging confluences’. In: N.K. Denzin and Y.S. Lincoln (eds) The Sage handbook of qualitative research ( $3^{\text {rd }}$ ed). London: Sage Publications Limited. pp. 163-188.

Groundwater-Smith, S. and Mockler, N. (2007) 'Ethics in practitioner research: An issue of quality’. Research Papers in Education, 22(2), pp. 199-211.

Haier, R. J., Jung, R. E., Yeo, R. A., Head, K. and Alkire, M. T. (2005) 'The neuroanatomy of general intelligence: Sex matters’. Neuroimage, 25(1), pp. 320-327.

Heron, J. and Reason, P. (1997) 'A participatory inquiry paradigm'. Qualitative Inquiry. 3(3), pp.274-294.

Hilliard, L. J. and Liben, L. S. (2010) 'Differing levels of gender salience in preschool classrooms: Effects on children’s gender attitudes and intergroup bias’. Child Development, 81 (6), pp. 1787-1798.

Hollinshead, K. (1996) 'The tourism researcher as bricoleur: The new wealth and diversity in qualitative inquiry’. Tourism Analysis, 1(1), pp. 67-74.

Holloway, I. and Wheeler, S. (2013) Qualitative research in nursing and healthcare, ( $\left.{ }^{\text {rd }} \mathrm{ed}\right)$. West Sussex: John Wiley \& Sons Limited.

Jones, S. and Myhill, D. (2004) “"Troublesome boys” and “compliant girls”: Gender identity and perceptions of achievement and underachievement'. British Journal of Sociology of Education, 25(5), pp.547-561.

Kezar, A. and Dee, J. R. (2011) 'Conducting multi-paradigm inquiry in the study of Higher Education organization and governance: Transforming research perspectives on colleges and universities'. In: J. C. Smart and M. B. Paulsen (eds) Higher education: Handbook of theory and research, Volume 26. London: Springer. pp. 265- 316.

Kimmel, M. S. (2005) The gender of desire: Essays on male sexuality. Albany, USA: State University of New York Press.

Laevers, F. and Verboven, L. (2000) 'Gender related role patterns in preschool settings. Can 'experiential education' make a difference?' European Early Childhood Education Research Journal, 8(1), pp. 25-42.

Lehrer, J. (2008) 'Annals of science the eureka hunt. Why do good ideas come to us when they do?’ New Yorker@ 
http://groups.psych.northwestern.edu/mbeeman/documents/NewYorker_Eureka.pdf $(08 / 3 / 16)$.

Leinbach, M. D. and Fagot, B. I. (1993) 'Categorical habitation to male and female faces: Gender schematic processing in infancy’. Infant Behavior and Development, 16(3), pp. 317-332.

LeMay Shieffield, S. (2004) Women and science: Social impact and interaction. New Brunswick, New Jersey, USA: Rutgers University Press.

Lenroot, R. K., Gogtay, N., Greenstein, D. K., Wells, E. M., Wallace, G. L., Clasen, L. S., Blumenthal, J. D., Lerch, J., Zijdenbos, A. P., Evans, A.C., Thompson, P. M. and Giedd, J. N. (2007) 'Sexual dimorphism of brain developmental trajectories during childhood and adolescence’. Neuroimage, 36(4), pp. 1065-1073.

Lipsitz-Bem, S.(1983) 'Gender schema theory and its implications for child development: Raising gender-aschematic children in a gender-schematic society'. Journal of Women in Culture and Society, 8(4), pp.598-616.

Lynch, M. (2015) 'Guys and dolls: a qualitative study of teachers' views of gendered play in kindergarten’ Early Child Development and Care, 185(5), pp. 679-693.

Martin, C. L. and Halverson, C. F.(1981) 'A schematic processing model of sex typing and stereotyping in children'. Child Development, 52(4), pp.1119-1134.

Martin, C. L. and Ruble, D. N. (2009) 'Patterns of gender development'. Annual Review of Psychology, 61, pp. 353-81.

Massey, D.( 2013) Space, place and gender. Cambridge:Cambridge Polity Press.

Meyer, E. J.(2010) Explorations of educational purpose, Gender and sexual diversity in schools, 10. Netherlands: Springer.

McCall, L. (2005) 'The complexity of intersectionality'. Signs, 30(3), pp.1771-1800.

McRobbie, A. (2004) 'Notes of postfeminism and popular culture: Bridget Jones and the new gender regime’. In: A. Harris, (ed) All about the girl: Culture, power, and identity. London: Routledge. pp.3-14.

Millett, K.(1971) Sexual politics. London: Rupert Hart-Davis Ltd.

Moi, T. (1999) What is a woman? And other essays. Oxford: Oxford University Press.

Morse, J. M. and Richards, L. (2002) Readme first for a user's guide to qualitative methods' London: Sage Publications Limited.

Morgan, G. (1997) Images of organization, $\left(2^{\text {nd }}\right.$ ed). Thousand Oaks, California, USA: Sage Publication Incorporated.

Moss, P. (2003) 'Gender and caring'. Delivered at Men in childcare: children need men too! European Conference, Edinburgh 8 December 2003 @ http://www.meninchildcare.co.uk/Conference-2003.htm (last accessed 7/10/2016).

O’Brien, K. (2009) Women and enlightenment in eighteenth-century Britain. Cambridge: Cambridge University Press.

O’Brien, M., Peyton,V., Mistry, R., Hruda, L., Jacobs, A., Caldera, Y., Huston, V and Ray, C. (2000) 'Gender-role cognition in three-year-old boys and girls'. Sex Roles, 42 (11/12), pp. 1007-1025.

Oates, B. J. (2006) Researching information systems and computing. London: Sage Publications Limited.

Peeters, J. (2013) 'Towards a gender neutral interpretation of professionalism in early childhood education and care (ECEC)', Revista Española de Educación Comparada, 21, pp. 119-144.

Putman, L. (1983) 'The interpretative perspective: An alternative to functionalism'. In L. Putnam, and M. Pacanowsky (eds) Communication and organizations, Beverly Hills, California, USA: Sage Publications Incorporated. pp. 31-54. 
Robson, S. (2012) 'Home and school: A potentially powerful partnership'. In: S. Robson and S. Smedley (eds) Education in early childhood: First things first. London: David Fulton Publishers Limited, pp. 56-74.

Rodd, J. (2012) Leadership in early childhood. London: Open University Press.

Rubin, G. (1975) 'The traffic in women: Notes on the "political economy of sex" '. In: R.R. Reiter (ed) Towards an anthropology of women. New York, USA: Monthly Review Press. pp. 179-180.

Ruble, D. N.,Taylor, L. J., Cyphers, L., Greulich, F. K. Lurye, L.E. and Shrout, P.E. (2007) 'The role of gender constancy in early gender development'. Child Development, 78(4), pp.1121 - 1136.

Ryle, R.(2012) Questioning gender: A sociological exploration. London: Sage Publication Limited.

Sadker, D and Zittleman, K. R. (2009) Still failing at fairness: How gender bias cheats girls and boys in school and what we can do about it. New York: Scribner.

Sama, J.M.(2013) We are equal, but not the same @http://jamesmsama.com/2013/12/08/weare-equal-but-not-the-same/ (last accessed 26/1/2016).

Sax, L. (2005) Why gender matters :What parents and teachers need to know about the emerging science of sex differences. New York, USA: Broadway Books.

Schoning, S., Engeliena, A., Kugeld, H., Schafer, S., Schiffbauerd, H., Zwitserloode, P., Pletziger, E., Beizai, P., Kerstinga, A.,Ohrmanna,P. Grebf, R.R.,Lehmanng, W. Heindeld, W., Arolt. V. and Konrada, C. (2007) 'Functional anatomy of visuo-spatial working memory during mental rotation is influenced by sex, menstrual cycle and sex steroid hormones', Neuropsychologia 45(14), pp. 3203-3214.

Schmitz, S.(2010) 'Sex, gender and the brain : Biological determinism versus social cultural constructivism'. In: I. Klinge and C. Weisemann, (eds) Sex and gender in biomedicine: Theories, methodologies, results. Guttenberg, Germany: University of Guttenberg, pp.

Schutz, A. and Luckmann, T. (1983) The structures of the life-world, Volume 2. Illinois, USA: Northwestern University Press.

Shaffer, D. R. (2009) Social and personality development, $\left(6^{\text {th }}\right.$ ed). Belmont, California, USA: Wadsworth Cengage Learning.

Siann, G.(1994) Gender, sex and sexuality (Contemporary Psychology). Bristol: Taylor \& Francis.

Silverman, D.(2006) Interpreting qualitative data: Methods for analysing talk text and interaction, ( $3^{\text {rd }}$ ed). London: Sage Publications Limited. Snow, M. E., Jacklin, C. N. and Maccoby, E. E. (1983) 'Sex-of-child differences in father interaction at one year of age'. Child Development, 54(1), pp. 227-232.

Snow, M. E., Jacklin, C. N. and Maccoby, E. E. (1983) 'Sex-of-child differences in father interaction at one year of age'. Child Development, 54(1), pp. 227-232.

SSSC (Scottish Social Service Council) (2015) The Standard for childhood practice: Revised 2015@http://www.sssc.uk.com/component/edocman/?task=document.viewdoc\&id=403\& Itemid =0 (last accessed 18/3/2016).

Swim, J. K. and Hyers, L. L. (2009) 'Sexism'. In T.D. Nelson (ed) Handbook of prejudice, stereotyping and discrimination. New York, USA: Psychology Press, Taylor and Francis Group. pp.407- 430.

Tobin, D., Menon M, Menon M, Spatta BC, Hodges EV, and Perry DG. (2010) 'The intrapsychics of gender: A model of self-socialization'. Psychological Review. 117 (2), pp.601-622.

Trawick-Smith, J., Wolff, J. Koschel, M. and Vallarelli, A. (2015) 'Effects of Toys on the Play Quality of Preschool Children: Influence of Gender, Ethnicity, and Socioeconomic Status’ Early Childhood Education. 43(4), pp.249-256. 
Walters, N. (2010) Living dolls: The return of sexism. London: Hachette Digital.

Weaver, K. and Olson, J .K. (2006) 'Understanding paradigms used for nursing research' Journal of Advanced Nursing, 53(4), pp. 459-469.

Weinraub, M., Clemens, L. P., Sockloff, A., Ethridge, T., Gracely, E. and Myers, B. (1984)

'The development of sex role stereotypes in the third year: Relationships to gender labelling, gender identity, sex-types toy preference, and family characteristics'. Child Development, 55(4), pp. 1493-1503.

Wolpert, L.(2014) Why can't a woman be more like a man. London: Faber and Faber Limited. 


\begin{tabular}{|l|l|l|}
\hline Subjects & Girls & Boys \\
\hline Art & $\sqrt{ }$ & \\
\hline Climbing frames (big physical equipment etc) & & $\sqrt{ }$ \\
\hline Computers & & $\sqrt{ }$ \\
\hline Construction toys: Building blocks etc & & $\sqrt{ }$ \\
\hline Dancing & $\sqrt{ }$ & \\
\hline Language & $\sqrt{ }$ & \\
\hline Maths & & $\sqrt{ }$ \\
\hline Outdoor & $\sqrt{ }$ & $\sqrt{ }$ \\
\hline Reading & $\sqrt{ }$ & \\
\hline Role play & $\sqrt{ }$ \\
\hline Sand & & $\sqrt{ }$ \\
\hline Singing & $\sqrt{ }$ & \\
\hline Water & & $\sqrt{ }$ \\
\hline Writing & $\sqrt{ }$ & \\
\hline
\end{tabular}




\section{Behaviours}

\section{polite}

\section{quiet}

\section{resilient}

\section{rough}

settle easily 
Mothers

Good manners

Get away with things

Feminine

Boisterous

Pink

Blue

Compliant

Boys will be boys

Gentle

Not feminine

Given cuddles

Resilient

Fathers

Quiet
Caring
Need protected

Boisterous

Strong

Protect girls 


\section{Participants say:}

They do not gender.

They give equal choice.

Nursery children are too young to be treated in a gendered manner.

Staff are trained so treat all children the same.
But also say:

Children need to be taught that they are different.

Children choices reflect their gender and these are often used to promote the children's learning.

Knowing if it is a boy or a girl helps participants to respond appropriately.

Staff respond differently to children on an individual basis. 


\section{Nature of gender}

\section{Learning}

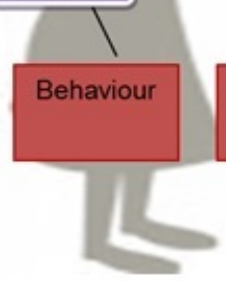

Parents

Not EYP 


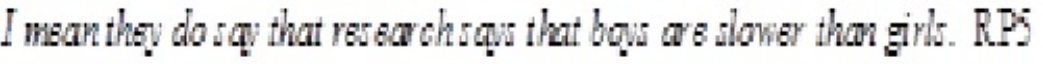

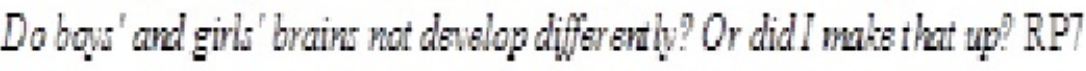
No I w a a course a Experiential Play ard they had a spoater wh said that there was a differen RP4 
Boys often get off with things more...than girls I would say...RP1

fathers can be quite protective of girls...boys get that much more leeway...RP6

even when they are younger...boys get away with a lot more...than girls will...even the mums will let the boys... managing the boys' behaviour is not so much a priority than managing the girls' behaviour...the boundaries.RP4

yes, and presenting themselves...girls presenting themselves...the girls have to speak a certain way...RP6

it isn't even just that it is...some of the wee boys in our establishment... there are no

boundaries there for them...RP4 